\title{
A Didactic Experience in Collaborative Learning Supported by Digital Media
}

\author{
Ricardo Cattafi and Christiane Metzner \\ Centro ISYS, Facultad de Ciencias, Universidad Central de \\ Venezuela, Caracas, Venezuela
}

\section{rcattafi@gmail.com cmetzner@isys.ciens.ucv.ve}

\begin{abstract}
Collaboration is a learning strategy used in various domains such as e-health, e-business, eeducation, e-government and e-research. In e-learning and under a constructivist approach, collaboration is expected to increase the performance of students. Although it can be used without digital media, given the pervasiveness of technology, their systematic application by educational institutions as instructional tools is nowadays common. In this work, we present our anecdotal experience to introduce collaborative learning at one of the main universities in Venezuela and analyze the results in terms of how students perceived what they learned, how they apprehended collaborative work and we describe a set of collaborative learning strategies with digital media and independent interaction tools that were chosen in this experience by students and teachers. These results will be used for improving the programs and courses in informatics aimed at preparing educators with a profile taking into account ICT's.
\end{abstract}

Keywords: Knowledge Society, Information Society, ICT in Education, Collaborative learning, e-learning

\section{Introduction}

It is in the so-called technologically excluded regions where e-education is still uncommon, and infostructure and infoculture (Newell et al., 1999) are least developed, but e-education can still be a key element for improving the digital literacy of the population. Using the definition of technological division, a classification based on availability of technology, about $15 \%$ of the world population provides nearly all of the world's technological innovations. About half of the world's population is able to adopt these technologies in production and consumption and the rest of the world's population is technologically disconnected, neither innovating at home nor adopting foreign technologies (The Economist, 2000). Political scientists, economists, and sociologists have long argued that inequality is a central obstacle to development; this inequality has changed little

Material published as part of this publication, either on-line or in print, is copyrighted by the Informing Science Institute. Permission to make digital or paper copy of part or all of these works for personal or classroom use is granted without fee provided that the copies are not made or distributed for profit or commercial advantage AND that copies 1) bear this notice in full and 2) give the full citation on the first page. It is permissible to abstract these works so long as credit is given. To copy in all other cases or to republish or to post on a server or to redistribute to lists requires specific permission and payment of a fee. Contact Publisher@InformingScience.org to request redistribution permission. during the last decades in Latin America and particularly in Venezuela. Many of the technologically excluded regions have a wide range of regional ills, including lagging rates of investment and growth and poor performance in science and innovation that can at least be reduced by considering technological solutions. According to a report by the World Bank [Perry \& al] widespread poverty can itself be a burden on 
growth. This pervasive poverty necessitates giving priority to policies simultaneously increasing growth and reducing poverty, such as investment in education and infrastructure.

Venezuela is one of the main world oil producers enjoying huge oil revenues and holding around $6 \%$ of the world's proven oil reserves. However, a considerable gap in infrastructure exists between main cities and many rural areas where no electricity or even canalization systems for clean water are available. Under these conditions, using technology effectively for improving living conditions such as health care, education and rural development is a challenging task.

The ICT expenditure (\%GDP) for Venezuela in 2004 was 5.3\%, a percentage comparable to that of Ireland (3.9), Germany (5.7) or France (5.9); in the USA the percentage is 8.8. On the other hand, the E-government Readiness Index for Venezuela stands at 0.52 on a scale of 0 - 1 while the numbers for Ireland, Germany, France and the USA are 0.66, 0.80, 0.54 and 1.00, respectively (World Bank, 2006). These numbers can be viewed as an indication that expenditure alone is not enough; technological improvement also requires the ability to use the technologies efficiently. This efficiency is also stated as a requirement of the Society of Knowledge (ECOSOC, 2000) and it is a serious competitive advantage for the countries having this ability. Considering that technology moves fastest, knowledge moves slowly and culture lags behind both, the question is which strategies, if any, can lead a country from a technologically excluded region towards a technological one. One of the first steps towards moving upwards technologically is the creation of a legislative framework enabling public and private organizations to develop, to acquire and to use the technologies. In the particular case of Venezuela, considered a technologically excluded region, policies regarding ICT have been approved. Some of the decrees emanating from government aimed at fostering the use of ICT in the local communities are compliance with open source software (Decree Nr. 3390), use of internet as a national priority (Decree Nr. 825) as well as the law for data messages and electronic signatures, the Telecommunications Law and the Law of Science and Information Technologies (LOCTI). However, very little or no planning and coordination at all can be found in practice. For example, there is little coherence between the actions sponsored by the government and the attitudes of the population. To overcome digital illiteracy the population has to be educated in the use and adoption of the new technologies and the educators, who should be the main arbiters in their use, don't use it. In Venezuela the CNTI (National Center for Information Technologies) is the main force behind eliminating digital illiteracy, but they have centered more on popularizing the notion of e-government than on educating the population in the use of ICT's for development. In our view, an educational policy is needed but it has yet to be written. For example, the site of the Ministry of Education (www.me.gov.ve) or the site of the Ministry of Higher Education (www.mes.gov.ve) does not have a single link related to the use of ICT's in education; in fact, they don't even have a link to the CNTI (www.cnti.gob.ve).

The adoption of ICT's for promoting collaboration in e-education is a worthwhile alternative toward becoming part of a Society of Knowledge. The aforementioned report of the World Bank gives the following indicators for E-Education/E- Literacy in Venezuela: no objective has been specified, there is no reported use of ICT's in education, and the only intervention is distance learning. In our view, in Venezuela an aggressive policy at all levels of the education system involving students/educators and coordinated and supervised by the corresponding ministries is essential for improving these indicators, and it has to exist along with:

i. A policy for developing common computational solutions allowing educators and learners to access computational and knowledge resources, to be used, understood and interpreted by those using them.

ii. Provision of the technological platform in educational institutions by outsourcing to third parties who would be in charge of maintaining the access, the non-obsolescence and the security of the resources.

iii. Separating the issue of using ICT's in e-education from e-government. 
iv. Including a basic course on ICT as teaching tools in all the undergraduate programs of Education Sciences and Pedagogy. Implementing this is a responsibility of universities and institutions specializing in Education Sciences and related areas of knowledge. (http://loe.cnu.gov.ve/listar_carreras.php?cod_area=2 )

The University of Carabobo (www.uc.edu.ve) is one of the universities in the higher education system of Venezuela consisting of some 80 public and private universities and technology institutions (http://loe.cnu.gov.ve/regiones.php); the university is organized hierarchically in seven faculties (Science \& Technology, Engineering, Health Sciences, Social Sciences, Education Sciences, Political \& Law Sciences and Dentistry) and their corresponding Departments. Most programs run on a semester basis; only Medicine and Science \& Technology are on an annual basis. The Faculty of Education Sciences offers professional degrees for students who plan to pursue teaching careers in different areas of specialization with Informatics being the one most recently created (http://www.face.uc.edu.ve/inicio2/index.php?option=com content\&task=view\&id=23\&Itemid= 35).

Informatics offers a hybrid program in education and informatics first launched in 2005 to satisfy the increasing demand for educators in informatics in the primary and secondary school system, which has until now mainly been supported by professionals with a degree in computer sciences or in information systems but with no schooling as educators. The Informatics' program is managed by the Informatics Department of the Faculty for Education Sciences while the Faculty of Sciences \& Technology offers the technological support and the lecturers for the courses in informatics. Students enrolled at the Faculty for Education Sciences can choose pursuing a minor in Informatics once they approve the second semester in Education and also by passing a test on basics in Informatics and on aptitude. There is a first group of 20 students enrolled in these studies who are expected to earn their degree in 2010.

Once accepted in the program, the students take the following courses: algorithms and data structures (Informatics I), advanced data structures and programming paradigms (Informatics II), data bases (Informatics III), computer architecture, operating systems, and optional courses centered on using ICT in education and on the design of teaching material.

Current facilities include rooms for 30 students with TV and A/C as well as one lab with 24 computers PIV with wireless Internet connection running under Windows XP or Linux Ubuntu.

Teaching / learning is traditional, pedagogic and not andragogic. The lectures in the classroom are goal-driven, the exams are written in the classroom, students have to implement a project, and there is little or no use at all of ICT's. The control and teaching / learning strategies are under the total responsibility of the educator.

In this work, we describe a collaborative learning experience with a group of students enrolled in the Faculty of Education Sciences and specializing in Informatics at the Universidad de Carabobo, Valencia, in Venezuela. This experience is part of an effort for improving student's programming skills having as a goal to identify student's acceptance of ICT's as a teaching / learning strategy and also to assess if the environment (access to technology, strategies, methods, student's skills) influences the education process. To this end the following process was used:

1. A survey was designed to obtain qualitative answers about technological literacy, interactivity, learning, resources, location, work method and connectivity. The survey can be retrieved from: (http://giasyta.ciens.ucv.ve/giasyta/repositorio/Encuesta_elearning_Colaborativo.pdf).

2. A group of 13 students signed up for a workshop on the GVO model (Cattafi \& Metzner, 2006). 
3. Design and application of a collaborative learning strategy.

4. The survey was handed out and the answers were evaluated.

In this work we start with a presentation of some fundamental issues such as the Knowledge Society, Digital Literacy, Learning Theories and Collaborative Work, followed by the presentation of the organizational model used, the learning strategy applied and our results.

\section{Background}

\section{The Knowledge Society}

The concept of Knowledge Society was coined in 1969 by Peter Drucker and was studied in depth in the 90's by researchers such as Robin Mansel (Mansell \& When, 1998) and Nico Stehr (Stehr \& Volker, 1999). Information societies are born from intensive innovation and use of ICT's where the increase in information transfer changes the way in which most activities in a modern society are performed; however, information is different from knowledge. Information is an instrument for transferring knowledge and knowledge is related to cognition, a process related to human capabilities of learning.

Until now, the Knowledge Society is more a utopia, than a reality; humanity is attempting to reach an evolutionary stage following the current Information Society through the opportunities opened up by the ICT's and humanization of society. In order to reach it, individuals have to go through a capacitating process for transforming information into knowledge. This is an educational process carried on by individuals and reinforced by the societies individuals belong to.

In this work, based on the publicly available documentation of the Knowledge Societies (ECOSOC, 2000), we consider the following stages for categorizing those trying to become a Knowledge Society:

a) Information Society: individuals belonging to the society have abilities for obtaining, interpreting, classifying, and storing information using digital media.

b) Cognitive Society: individuals belonging to the society have abilities to analyze and process information in order to generate new knowledge

c) Innovation Society by transforming new knowledge: this is the process generally associated with innovation. It is expected that a high percentage of the population can reach this state. However, this is not an easy task as it requires resources to be provided by all stakeholders (individuals, governments, and organizations), definition of norms and regulations for performing legal transactions, and knowledge about the complete process starting from information gathering until innovation occurs. An educational process is essential at this last stage when creating the envisioned society.

To become a Knowledge Society, a population has to be digitally literate. Digital literacy is a learning process based on each individual being responsible for personal growth and but it is also a commitment for the societies who in the end have the task of educating its members.

Digital literacy is not an absolute notion as an individual may have some degree of literacy, being able to use ICT's at least in correspondence to the degree. In order to classify the members of a social group according to digital literacy, in this work we propose the following taxonomy of four, non-exclusive levels for classifying the digital literacy level of individuals; each level should have a set of learning strategies. 
Level 1: an individual has abilities to collect, interpret, classify, store, analyze and acquire knowledge; to innovate using relevant, up to date and reliable digitized information being also capable of communicating person to person (p2p), person to group (p2g), group to group ( $\mathrm{g} 2 \mathrm{~g})$ and of successfully performing transactions (commercial and non-commercial) and of using any available digital media without intervention of a third party.

Level 2: an individual is able to communicate using at least one of the previously stated strategies, to obtain and interpret some kind of information and to perform non-commercial transactions using at least one digital media.

Level 3: an individual can communicate only $\mathrm{p} 2 \mathrm{p}$ and read information using at least one digital media.

Level 4: an individual requires a third party in order to obtain information, to communicate or to perform transactions. This level is associated to digital illiteracy.

An individual can satisfy the conditions of more than one level and in order to be classified at the first three levels she has to go through a learning process. From a strictly instrumental point of view, the ability of reaching Levels 1, 2 or 3 is subject to the following three premises:

i) Having access to digital media

ii) Being able to use digital media

iii) Retrieving pertinent, reliable and up to date information

Anyone satisfying these premises should be able to obtain information and use it in order to gain new knowledge, and the same sources of information should be available to knowledge providers and learners. Knowledge providers are no more the owners of information; they are the experts in the use and interpretation of information in a particular area of knowledge and they are also the motivating agents in a learning process.

Current technologies in computers, cellular phones, interactive TV portable multimedia devices, VoIP, PDAs, have a central role in restating at least the following three aspects regarding educational activities:

i) Obtaining, classifying and storing information

ii) Communication among participants

iii) Performing transactions.

Besides classifying individuals at one of the levels $(1,2$, or 3$)$ an interaction strategy is also needed. Regarding communication, digital media enable different strategies:

i) p2p: with voice and mail tools as well as text messages and facsimiles

ii) p2g: appropriate tools are blackboards, blogs, and email lists

iii) g2g: appropriate tools are forums, wikis, teleconferencing, and chat rooms.

A main benefit of using digital media for communication derives from the multimedia facility: being able to send and receive voice, video, images, and data over a unique channel contributes to a fluid and rich communication.

From the learning perspective, learners can also communicate their expectations, doubts, suggestions, and ideas to all the participants; on the other hand, knowledge providers can transmit relevant information, define working rules, answer questions, and manage the learning process. Ideally any individual at the first three levels of digital literacy may communicate by any of the 
above described strategies; however, many different factors can hinder individuals in reaching the ideal:

i) Socio-cultural factors, such as standard of living, religion or beliefs.

ii) Cognitive factors, such as motivation or abilities.

iii) Aptitude factors or attitude towards learning objectives.

iv) Motivational factors expressed as the need to learn.

v) Difficulties accessing resources.

Some of these factors are frequently found in technologically excluded regions and may have influenced the results of this work.

\section{Learning Theories}

Learning is grounded in well-defined theories: Constructivism, Cognitivism, and Behaviorism (Shunk, 1997) and learning strategies are based on these theories. One of the possible strategies in constructivism is the collaboration among group members interacting and sharing knowledge, experiences, and information sources in order to reach some stated goal and generating new knowledge.

Learning theories define general concepts and are useful as a discipline of thought in theoretical comprehension as well as in applications (Shunk, 1997). However, they are partial views since they generally focus on certain aspects of a learning situation. Behaviorism considers that only external observations explain a behavior. It is based on the assumption that learning is the result of associating a stimulus to a response. Cognitivism in contrast studies how learning occurs based on the cognitive processes, which are supposed to exist in a learner (Shunk, 1997). Constructivism is a philosophy of learning based on the assumption that knowledge does not exist external to a learner; it is built internally through a reflection process depending on the learner's own experience. (Duffy \& Jonassen, 1991; Wilson, 1996). The learner builds his view and meaning of the world he lives in. In this theory, the learning context plays a central role for a knowledge building process.

\section{Teaching/Learning Strategies}

They provide learners with authentic and significant experiences in a relevant context allowing them to transfer the knowledge acquired in a scholar or academic context into a real context (Shunk, 1997). Instructional design uses strategies aimed at the individual such as tutorials, research and development, training, simulation, up to date information, exploration, scientific method and goal centered scenarios. Group strategies can be designed such as forums, discussion, expert view, multiple perspectives, informal collaboration, best practices and intelligent agents (Cattafi, 2006).

\section{Collaborative work}

Computer-Supported Collaborative Work (CSCW) is a multidisciplinary research field dealing with the development of tools and techniques for providing support to multiple persons performing shared tasks on a network or a distributed platform (Greif \& Cashman, 1984).

Although the terms CSCW and Groupware are generally used indistinctly, some authors point out that CSCW focuses not only on the study of groupware tools and techniques but also on the social, organizational and psychological effects it has, while Groupware is used for applications 
integrating concurrent activities of multiple users working on a single project connected on a network or Internet (Wilson, 1991). It is also worthwhile to note that in the definition of CSCW "collaborative" and "cooperative" are also used indistinctly by some authors, while others consider a semantic difference between the two concepts (Dillenbourg \& Schneider, 1995); in some publications CSCW stands for Computer-Supported Cooperative Work. Dillenbourg and Schneider argue that the difference is how the tasks to be accomplished are decomposed: in cooperation, tasks are decomposed hierarchically into independent subtasks, while in collaboration the cognitive processes (tasks) are decomposed hetero- hierarchically into interchangeable layers. On the other hand, coordination is different as it denotes the dependency management between activities and support of interdependencies among participants (Bordeau \& Wasson, 1997). Coordination is the process used to exchange information among individuals using a common system of symbols, signs, and behavior; cooperation requires coordination when the results are to be integrated while collaboration is a synchronous process. Communication is essential for any coordination / collaboration activity.

When developing a collaborative/cooperative project some degree of structure of the group is required. The structure is the result of an organization, which can be viewed as a social or as an administrative entity (Chiavenato, 1999).

As social entities, organizations consist of people wanting to reach goals. Every goal requires some work to be accomplished. The work is decomposed into parts and the different parts are assigned to members of the organization. Formal organizations are based on a structure that is rigorously defined in official documents, on a rational division of the work to be accomplished specializing the functions and entities by activities. In informal organizations the structure emerges on the fly as the outcome of human relations based on friendship or antagonism between individuals playing specific roles in the underlying formal organization; hence, groups emerge that are not considered in the official documents.

As administrative entities, organizations are responsible for making plans, integrating, structuring resources, creating entities, and assigning activities. According to the degree of formality of the relationships between the members of an organization, different kinds of organizational structures can be identified: bureaucratic, team, spontaneous cooperation, based on teams and collaborations (Pasache \& Arancibia, 2000). Whether communications are synchronous or asynchronous allows classifying organizations into hierarchical, dynamic, and virtual (Whittaker et al, 2001). Each kind of organization shows different degrees of collaboration between its members (individuals or groups) when accomplishing their tasks.

In order to contextualize collaboration as an interaction strategy it is useful to take into account different kinds of interactions: conversational, transactional, and collaborative. A conversational interaction is characterized by the exchange of information between two or more participants with the main purpose of establishing a relationship using tools such as phone, email, or instant messaging. A transactional interaction includes the exchange of transactional entities specifying the relation among participants. As an example, in a commercial context the exchange of goods (transactional entity) for money defines one participant as a buyer and the other one as the seller. In a collaborative interaction, the main purpose is changing the state of the collaborative entity by the participants; it is the opposite of a transactional interaction where the collaborative entity is relatively unstable such as developing an idea, creating a design, or reaching some goal and the entity will change states until it reaches a stable form as a consequence of the participant's collaborative interactions. Tools enabling these kinds of interactions are known as document managers, threaded discussions, and shared audits. 


\section{Collaborative Tools}

The tools enabling collaborative strategies can be divided into tools supporting a method and those supporting an area. In this work, we consider only web-based tools, which can be classified as communicational, collaborative, or teleconferencing tools. Communicational tools supporting collaboration are used to send messages, files, data, or documents enabling information sharing among participants. Collaborative tools enable group work and they include electronic calendars, Project Management Systems, Workflow Management Systems, Knowledge Management Systems, Extranets, Bookmarking, wikis, blogs, and Discussion Groups. Teleconferencing tools enable interactive information sharing; every participant can set data in a shared blackboard; also video and audio are used for information exchange; forums are used for asynchronous virtual discussions and chat rooms are the platforms for synchronous virtual discussions.

\section{e-learning}

Web education or e-learning is a strategy for teaching/learning where all the educational activities use digital media and software tools on Internet as the communicational or transactional platform. Computer mediated communication can be used in various forms in the teaching/learning process: for content publication, for support of administrative tasks, to increase teaching availability via electronic tutorials and to promote collaborative learning enhancing communications between students and teachers. An e-learning strategy can be collaborative / cooperative (group or individual) and encompasses cognitive procedures for self-control and self-regulation to be applied on attention, memory, and comprehension; in the collaborative form, activities are to be performed in the classroom (virtual or real) by small groups of students after the explanations of the teacher.

Information technologies supporting e-learning should possess the following properties: accessibility, multiplatform, multimedia format for displaying information, graphical interfaces, group restricted access, hypertext structure of information and content, interpersonal communication, student follow-up, tools for collaborative work, student management and control, creation of evaluation and auto evaluation assignments, access to learning information and content, access to information on Internet, and interactions among group members. When the teaching strategy is elearning, learning can be viewed in terms of the increasingly skilled participation of the members in a knowledge-based community.

\section{A Collaborative Organization Model}

In this work, we use an organizational meta model of generic virtual organizations (GVO) defined as consisting of the following entities: Person, Functional Unit, Role, Procedure, Rule, Goal, Interest, Virtual Existence, Obligations, Knowledge, Resource, and Behavior. The property of "generic" means that the model is defined for social organizations (formal or informal) with any number of persons, machines, roles, functional entities and organizations in domains such as e-health, e-business, e-learning, e-government and e-research. The property of "virtual" outlines the fact that its members can be geographically distributed; they communicate and / or coordinate their activities using ICT's and they have a common long-term goal or interest. The details of the GVO meta model are beyond the scope of this work, however, the model can be retrieved in (Cattafi \& Metzner 2006a).

\section{A Collaborative Experience}

The under-performance of a 45-student undergraduate course in informatics at the Universidad de Carabobo, Valencia, Venezuela, for those majoring in Education with a minor in Informatics, 
aimed at the teaching of algorithms and data structures in $\mathrm{C}++$ during a regular semester in 2006 motivated the department in charge to explore other motivating teaching/learning strategies.

A workshop for the Informatics I course with a collaborative teaching/learning strategy was designed to introduce fundamental concepts needed to successfully complete the course, such as programming paradigms, data structures, control structures, algorithms, modularization techniques, programming techniques in $\mathrm{C}++$, sorting and searching. Our sample was a group of 13 students with similar education levels and with no previous knowledge about the topics of the informatics course, and they voluntarily enrolled in the workshop. The strategy comprised the following six sessions:

- Introduction to collaborative learning: a 90-minute session was used to explain the dynamics in collaborative learning. The collaborative model was introduced and compromises were reached about how the students would apply the model.

- Introduction to collaborative practice: a 45-minute session in which students were assigned the task of solving a 145-word puzzle using the collaborative model. Groups were created, a goal was set, rules were defined, resources were made available, and the learning and teaching method discussed. The task was solved after 20 minutes and at the end of the session the activity was evaluated.

- Collaborative learning: a virtual space with synchronous distributed interactions was used during a 120-minute session. The students had to solve an evaluation covering five different topics also included in the Informatics I course. Activities were randomly distributed to all groups. Each group was supposed to find and interpret some information about the topic, use knowledge resources, state a solution, agree on the solution, prepare a summary, and mail it to the participants. The set of rules previously agreed on had to be followed.

- Presentation of new knowledge: a 120-minute session held in the classroom with the purpose of exchanging synchronously any newly acquired knowledge. Each group presented some theoretical aspects of the topic and a problem to be solved collaboratively by all groups during this session.

- Evaluation: each participant had to fill out an individual evaluation instrument.

- Control: a 40-question poll was used.

In order to create a form of organization allowing collaborative interactions among students, teachers and other individuals acting as external knowledge resources the GVO meta model was instantiated as follows for this experience:

- Organization: an e-learning virtual organization

- Members: students, teachers, external experts

- Roles

○ Learner: played by the students

- Facilitator: the teacher viewed as a knowledge source

- Mediator: the teacher

- Third parties: other participants

- Procedures: the following procedures were defined:

- Starting an activity

$\circ$ Installing an activity 
$\circ$ Obtaining information

- Interpreting the information

- Agreeing on a solution

○ Closing an activity

- Ending an activity

- Functional Units: five student groups

- Rules were clearly defined before any activity is started

- Goal: to learn about the specific topic assigned to each group

- Virtual existence: the groups did not publish on the web, therefore they did not have a virtual existence

- Interests: are associated to each role

- Learner: learn a new topic

○ Facilitator: provide information and motivate

- Mediator: compliance with rules

- External experts: provide knowledge resources

- Obligations: not formally specified. All the participants agreed to follow the rules

- Behavior: the rules of behavior used were explicitly defined and they can be retrieved from $<$ http://giasyta.ciens.ucv.ve/giasyta/repositorio/Reglas_e-learning_Colaborativo.pdf $>$

- Knowledge: each participant playing a particular role contributed with previously acquired knowledge. Bibliographic resources on paper and on the web are included as knowledge.

- Resources: the following kinds of resources were used:

- Location: every student used a virtual space at his convenience.

- Time: 120 minutes

- Tools: participants used computers, phone, fax, microphones, and cameras with the corresponding technological tools: browsers, messengers, web sites, search, tutorials, editors, spreadsheets, and chat with digital media.

The students were also encouraged to participate actively during the 120 minutes of the collaborative learning phase in the above-described strategy. The students used their own resources or those available at chat rooms and they received information about the starting time of the event. During the session all student observations were registered and at the end of the session students had to send a report via email to the teacher with the details of their activity and the solution to the stated problems.

\section{Results}

Once the evaluation session was finished the students were asked to fill out a survey consisting of 40 questions arranged in sections. (http://giasyta.ciens.ucv.ve/giasyta/repositorio/Encuesta_elearning_Colaborativo.pdf). Each section considered a specific topic: digital literacy, interactions, learning, resources, location, work method and connectivity. For the purpose of interpretation and analysis the answers were tabulated; however, the survey's goal was not a statistical analysis of the issues as the sample was not statistically significant. It is to be considered as anecdotal in- 
formation. Even so, the results can guide us to spread the use of collaborative education strategies supported by ICT's. In what follows, the results for some of the questions in the survey are presented and analyzed.

\section{Satisfaction with the Collaborative Model}

One of the main questions we wanted answered was on the overall engagement of the learners with the model and its activities. As can be seen from Table 1, no one considers the model inadequate or shows dissatisfaction with the interaction with peers or teachers. These results encourage the department to further explore and apply the model.

\begin{tabular}{|c|c|c|c|c|c|}
\hline \multicolumn{7}{|c|}{ Table 1. Collaborative Model } \\
\hline Topic & Not satisfied & Good & Very Good & Excellent & No answer \\
\hline Use of model & 0 & 8 & 2 & 2 & 1 \\
\hline Teachers attention to students & 0 & 4 & 5 & 2 & 2 \\
\hline Satisfaction with peers & 0 & 1 & 8 & 3 & 2 \\
\hline
\end{tabular}

These answers show that the organization according to the GVO model was fully understood by all participants. Each participant was aware of his role, goal and responsibilities, which are important factors for integrated and structured interactions. Teacher's attention to students was wellrated overall; however, in our view there were some difficulties: attending more than two chat conversations simultaneously is probably the central one, particularly if there are live questions or if an explanation required the use of video conference. These elements need a better technology and/or a different strategy for using it. The satisfaction of students with peers may be due to them previously knowing each other, and everybody was identified with the team.

Opinions regarding the preference of the virtual classroom, shown in Table 2, were almost equally divided although there were some missing answers. Participants agreed on preferring to work without support of a third party, and the number of participants was considered adequate; a minority brought in a friend or a family member to support them in the activities. These results suggest that most participants are digital literate (at levels 1 to 3 ) and that something has to be done for improving familiarity with virtuality. Not being motivated all the time was allegedly due to loss of energy. This may have had to do with the length of the case, as described in the previous section.

\section{Table 2. Student perception}

\begin{tabular}{|c|c|c|}
\hline Question & Yes & No \\
\hline $\begin{array}{l}\text { Do you prefer the Virtual } \\
\text { Class Room? }\end{array}$ & 6 & 5 \\
\hline $\begin{array}{l}\text { Adequate number of partici- } \\
\text { pants }\end{array}$ & 11 & 2 \\
\hline Did you work without help? & 10 & 3 \\
\hline $\begin{array}{l}\text { Were you motivated all the } \\
\text { time? }\end{array}$ & 9 & 4 \\
\hline
\end{tabular}


Everyone in this experience preferred the collaborative model over the individualistic/competitive one and the participants were satisfied with how they interplayed to build knowledge collectively. (Table 3)

\begin{tabular}{|l|l|l|l|l|}
\hline \multicolumn{5}{|c|}{ Table 3. Student's Perception of Learning } \\
\hline Item & $\begin{array}{l}\text { Not } \\
\text { satisfied }\end{array}$ & Good & $\begin{array}{l}\text { Very } \\
\text { Good }\end{array}$ & Excellent \\
\hline $\begin{array}{l}\text { Rate perception of what you } \\
\text { learned }\end{array}$ & 0 & 9 & 3 & 0 \\
\hline
\end{tabular}

\section{Meeting of Goals}

Independently of the students' preferences, the students mostly agreed that at least $50 \%$ of the learning- process goals were met (Table 4).

\begin{tabular}{|l|l|l|l|l|}
\hline \multicolumn{5}{|c|}{ Table 4. Goals } \\
\hline Item & $\begin{array}{l}\mathbf{2 5} \\
\text { \% }\end{array}$ & $\begin{array}{l}\mathbf{5 0} \\
\mathbf{8 0} \%\end{array}$ & $\begin{array}{l}\mathbf{8 1 -} \\
\mathbf{9 9} \%\end{array}$ & $\begin{array}{l}\mathbf{1 0 0} \\
\%\end{array}$ \\
\hline $\begin{array}{l}\text { Goals were } \\
\text { met }\end{array}$ & 1 & 10 & 1 & 1 \\
\hline
\end{tabular}

\section{Conclusions}

In this work, we presented our first anecdotal experience to introduce collaborative learning in our environment. Based on our findings, the motivation and disposition to work collaboratively to create a knowledge-based community became apparent. We also found that a high percentage of the students have no access to IT resources, having to pay for using hardware and software at Internet centers where the connectivity is poor or working conditions are not adequate. The overall cognitive and motivational outcome can be valued as positive based on the grades of the evaluation session (the average grade was 16.8 on a 20 point scale) and on students' preferences for the collaborative strategy. The GVO model was an excellent guideline, providing precision in what to define and what to evaluate. We are aware that more efforts have still to be made for improving students' skills and abilities prior to the introductory course in informatics, more computing resources have to be made available, and shorter sessions might improve the motivation of learners. We are aware that educators need to be actively involved in using ICT's to change education strategies. For this end, the use of ICT's should be included in the programs of studies in education and life-long learning facilities must also be provided for all educators. In addition, the collaborative strategy is not a silver bullet for e-learning; collaboration should be applied only when adequate technological and educational conditions are met supporting rigorous task specification and control of knowledge providers' activities. These results will be used for improving the programs and courses in informatics aimed at preparing educators with a profile taking into account ICT's.

Some additional remarks about some weaknesses that could have had an impact on our results are: 
a. The students enrolled in the program are generally not inclined to scientific studies. Although the faculty is in the Sciences in Education department, its priority is human behavior and learning strategies. It is a humanistic oriented faculty.

b. The Academic index AI (http://loe.cnu.gov.ve/pna.php) required by the National Council of Universities (CNU) for entering into the university system is lower for Education than for Basic Sciences.

http://loe.cnu.gov.ve/ver info institutos.php?cod uni $=0000000003 \& \operatorname{cod}$ region $=2$ and http://servicios.universia.edu.ve/rediseno/contenidos/preuniversia/detalle.php?id_content $=4158)$

c. The use of ICT's is not a priority. Teachers have a preference for techniques for which they do not have to deal with a technology they have not mastered.

d. Students with previous knowledge in Informatics have a competitive advantage. Teachers should involve those students as drivers for the learning of other students.

\section{Acknowledgements}

This work is supported by project No. PG 03.13.4241.2003, Consejo de Desarrollo Científico y Humanístico, Universidad Central de Venezuela and Grant No. 200600173/FONACIT.

\section{References}

Bordeau, J., \& Wasson, B. (1997). Orchestrating collaboration in collaborative telelearning. Artificial Intelligence in Education, 565-567. IOS Press.

Cattafi, R. (2006). WAF: Un framework para el desarrollo de componentes con agentes de software. Trabajo de Grado de Maestría en Ciencias de la Computación", UCV. Caracas, Venezuela 2006

Cattafi, R., \& Metzner, C. (2006). Organizaciones virtuales genéricas extendidas. Draft to be retrieved from http://giasyta.ciens.ucv.ve/giasyta/repositorio/OVGE.pdf

Chiavenato, I. (1999). Introducción a la teoría general de la administración (5 $5^{\text {th }}$ ed.). Mexico: McGrawHill.

Dillenbourg, P., \& Schneider, D. (1995). Collaborative learning and the Internet. Proceedings of ICCAI 1995. Available at http://tecfa.unige.ch/tecfa/tecfa-research/CMC/colla/iccai95_1.html

Duffy, T. M., \& Jonassen, D. H. (1991). Constructivist: New implication for instructional technology. Educational Technology, 31 (5), 7-21.

ECOSOC. (2000). Available at http://www.un.org/spanish/documents/esc/doc2000.htm

Greif, I., \& Cashman, P. (1988). CSCW: A book of readings. San Mateo, CA, USA: Morgan Kaufmann.

Mansell, R., \& When, U. (1998). INK - Knowledge societies information technology for sustainable development. Oxford University Press. Available at http://www.sussex.ac.uk/spru/1-4-9-1-1-2.html

Newell, S., Scarbrough, H., Swan, J., \& Hislop, D. (1999). Intranets and knowledge management: Complex processes and ironic outcomes, Proceedings of the 32 Annual Hawaii International Conference on System Sciences, Maui, HI, USA.

Pasache, C., \& Arancibia, D. (2005). Sistemas distribuidos: Computación colaborativa. Monografía.

Perry, G. et al. (2004). Poverty reduction and growth: Virtuous and vicious circles. World Bank, Latin American and Caribbean Studies

Schunk, D. (1997). Teorías del aprendizaje ( $2^{\text {nd }}$ ed.). México: Prentice Hall. 
Stehr, N. \& Volker, M. (1999). The sociology of knowledge. In H. Newby (ed.), International library of critical writings in sociology. Available at http://www.uofaweb.ualberta.ca/sociology/stehr.cfm

The Economist. (2000, June 24). Sachs on globalization

Whitaker, P., MacKinnon, J., \& White, D. (2001). Virtual desire and virtual reality. A case study highlighting the reality of becoming a virtual organization. Proceedings of the 2001 BITWORLD Conference, Cairo, Egypt

Wilson, B. G. (1995). Metaphors for instruction: Why we talk about learning environments. Educational Technology, 35 (5), 25-30.

World Bank. (2006). Global trends and policies: Information and communications for development.

\section{Biographies}

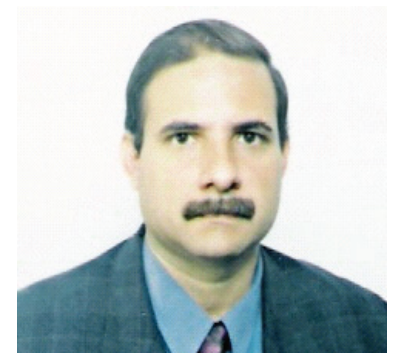

Ricardo Cattafi is a professor at the Science and Technology Faculty and at the Education Science Faculty at Universidad de Carabobo, Venezuela. He is currently a doctoral student in Computer Sciences at the Faculty of Sciences, Universidad Central de Venezuela. His research interest is distributed artificial intelligence and its application in virtual organizations.

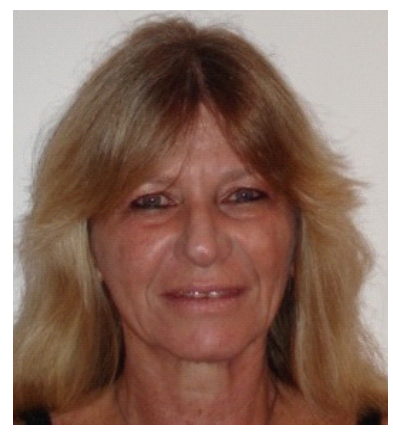

Christiane Metzner is a full-time professor at the Computer Science School, Universidad Central de Venezuela. Her professional experience spans over 25 years, with the last several years focused on software engineering, particularly design patterns, metrics and technologies for web development. 